\title{
Multichamber Device for Sheet-Metal Treatment Under Pressure
}

\author{
Musayev A.A. \\ Laboratory of Metals, Alloys and Composite Materials \\ Kh.I. Ibragimov Complex Institute of \\ the Russian Academy of Sciences \\ Grozny, Russia \\ brain_95@mail.ru
}

Betrakhmadov R.V.

Laboratory of Metals, Alloys and Composite Materials

Kh.I. Ibragimov Complex Institute of the Russian Academy of Sciences

Grozny, Russia

brv1964@yandexs.ru

Saidov M.A.

Department of Applied Mechanics and Engineering Graphics

Grozny State Oil Technical University named after academician M.D. Millionshchikov

Grozny, Russia

saidoff@bk.ru

\section{Mazhiyev K.Kh.}

Laboratory of Metals, Alloys and Composite Materials

Kh.I. Ibragimov Complex Institute of

the Russian Academy of Sciences

Grozny, Russia

m.k.kh@mail.ru

\begin{abstract}
The multichamber device belongs to pulsed methods of forming and is mainly intended for use in small-scale production. The process of forming is carried out under pressure of an elastic disk due to kinetic energy of the piston accumulated throughout the working cycle. The piston is accelerated under pressure of high-temperature gas, which is formed in the combustion chamber during the combustion of gaseous fuel mixes. The paper suggests design modifications of the existing device in order to expand its technological potential by increasing the kinetic energy of the piston. This is achieved due to end-to-end channel in the elastic disk and the piston connecting a head-end volume of the working cylinder with the combustion chamber, where the backpressure valve is installed at the end of the channel on the side of the combustion chamber.
\end{abstract}

Keywords $\rightarrow$ heet forming, elastic medium, gas forming, kinetic energy, backpressure valve, multichamber device, fuel mix, gas pressure

\author{
Elmurzayev A.A. \\ Department of Technological Machines and Equipment \\ Grozny State Oil Technical University named after \\ academician M.D. Millionshchikov \\ Grozny, Russia \\ ayub_777@mail.ru
}

Shuaipov A.A.

Department of Applied Mechanics and

Engineering Graphics

Grozny State Oil Technical University named after academician M.D. Millionshchikov

Grozny, Russia

saidoff@bk.ru

Tsamayeva P.S.

Department of Technological Machines and Equipment Grozny State Oil Technical University named after academician M.D. Millionshchikov

Grozny, Russia

pstsam@mail.ru

Maseva L.M.

Department of Health and Safety

Grozny State Oil Technical University named after academician M.D. Millionshchikov

Grozny, Russia

lizamasaeva@mail.ru

\section{INTRODUCTION}

At present, the limited production is quite relevant for many branches of industry. Therefore, the development of technology and equipment increasing the efficiency of limited production is still an urgent problem. One of the ways to increase the efficiency is the use of pulsed methods of treatment under pressure.

Such devices are especially efficient in limited production due to their simplicity and low cost. Gas mixtures are used as energy carriers in these devices.

There are devices for sheet forming, which ensure forming under gas pressure during the combustion of gaseous fuel mix [1-12]. Due to relatively low pressure of combustion products, the maximum pressure of combustion products makes $20 \ldots 25$ $\mathrm{MPa}$. This pressure ensures forming of parts from sheet workpieces with quite small thickness, in particular steel workpieces up to $1.5 \mathrm{~mm}$ thick. Besides, the forming of parts of 
complicated configuration with small radiuses of curvature is quite difficult. In general, this reduces technological options of such forming.

The disadvantage of the existing analog of the device $[6,7]$ is the following. The components of a fuel mix (combustible gas and compressed air) enter the combustion chamber from the head-end volume of the working cylinder through a ring gap between the piston and the wall of the working cylinder. The combustion of the fuel mix in the combustion chamber under the pressure of combustion products triggers the working stroke of a piston thus initiating a certain kinetic energy and the forming process. This is accompanied by the leakage of combustion products from the combustion chamber through a ring gap between the piston and the wall of the working cylinder. This reduces kinetic energy of the piston, causing the forming process, and finally reduces the technological parameters of this device.

The purpose of the study is to expand the technological potential of the multichamber device for treatment of sheet material under pressure (further to be referred to as the multichamber device) by increasing the kinetic energy of the piston.

The purpose is achieved by the improvement of design parameters of the multichamber device, in particular the elastic disk and the piston. This is achieved due to end-to-end channel in the elastic disk and the piston connecting a head-end volume of the working cylinder with the combustion chamber, where the backpressure valve is installed at the end of the channel on the side of the combustion chamber.

This is implemented within the multichamber device shown in Fig. 1 and 2. The multichamber device includes the case 1 with the combustion chamber 2 and the working cylinder 3 , where the piston 4 with the elastic disk 5 is installed at its end face, and the die holder 6 connected by bolts 7 and nuts 8 to the case 1 . The matrix 9 serving the tool is installed in the die holder 6. The inlet 10 and exhaust valves 11 are placed on the wall of the working cylinder 3 . The end-to-end channel 12 connecting the head-end volume 13 of the working cylinder 3 to the combustion chamber 2 is made in the piston 4 and the elastic disk 5. On the end of the channel 12 from the combustion chamber 2 the backpressure valve 14 is installed, which case 15 is fixed at the lower end face of the piston 4 . On the side surface of the piston 4 the seal rings 16 are placed. The sleeve 17 holding the piston 4 is installed in the combustion chamber 2 . The additional combustion chamber 18 with spark plugs 19 is attached to the case 1 . The additional combustion chamber 18 is connected to the combustion chamber 2 through the channel 20. In the lower part of the case 1 the exhaust valve 21 is installed. In the top part of the case 1 the ring cavity 22 is installed with the ring piston 23 . The processed workpiece 24 is located between a die holder 6 and the ring piston 22 .

The multichamber device operates as follows. Liquid or compressed air is supplied under pressure to the ring cavity 22 , at the same time the ring piston 23 tightens a flange part of the workpiece 24 . Then the combustible gas, for example natural gas or propane-butane, is supplied via the inlet valve 10 into the head-end volume 13 with exhaust valves 11 and 21 being closed. Gas from this cavity through the channel 12 and the backpressure valve 14 gets to the combustion chamber 2 , and then through the channel 20 - to the additional combustion chamber 18 . Then via the inlet valve 10 the compressed air is supplied to the head-end volume 13 .

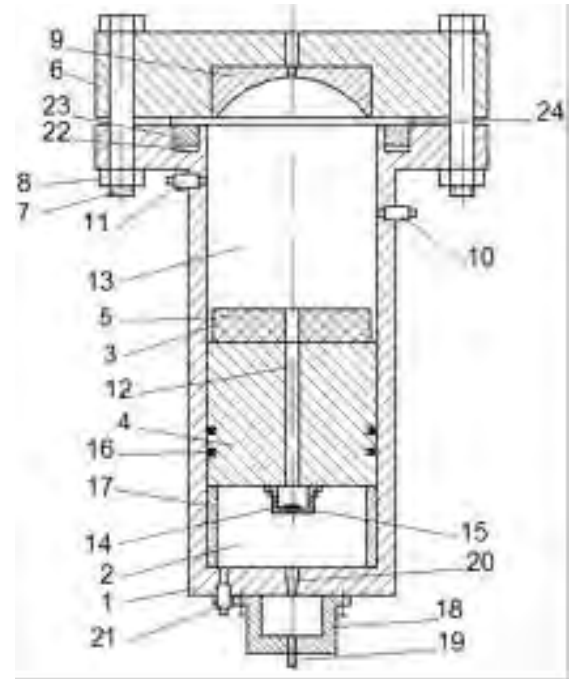

Fig. 1. Multichamber device for treatment of sheet materials under pressure: 1case; 2-combustion chamber; 3-working cylinder; 4-piston; 5-elastic disk; 6-die holder; 7-bolt; 8-nut; 9matrix; 10-inlet valve; 11, 21-exhaust valve; 12-end-to-end channel; 13-head-end volume; 14 backpressure valve; 15-case; 16 -seal ring; 17-sleeve; 18 -additional combustion chamber; 19-spark plug; 20-channel; 22-ring cavity; 23-ring piston; 24-workpiece.

At the same time the compressed air, forcing out the combustible gas from the head-end volume 13, is supplied to the combustion chamber 2 through the channel 12 and then to the additional combustion chamber 18 . As a result, fuel mix is formed in the combustion chamber 2 and the additional combustion chamber 18 , and the head-end volume 13 is filled with compressed air. The fuel mix in the additional combustion chamber 18 is ignited via the spark plug 19.

Due to small volume of the additional combustion chamber 18 the fuel mix is quickly burnt, and the flame is jet out through the channel 20 to the combustion chamber 2 . It ensures intensive combustion of fuel mix in the combustion chamber 2 .

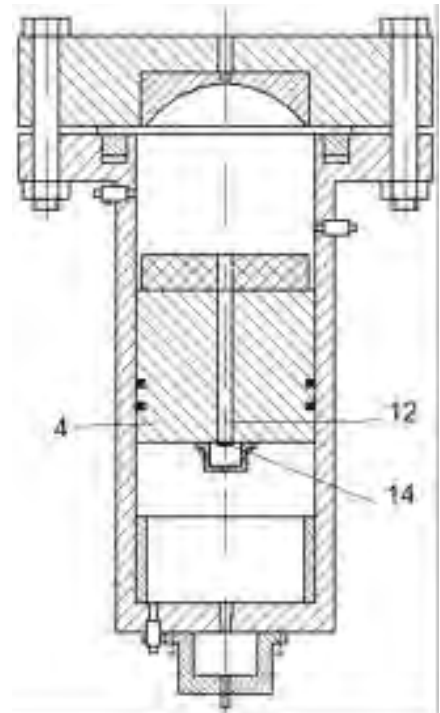

Fig. 2. Multichamber device during the working cycle 4-piston; 12-end-to-end channel; 14-backpressure valve. 
In 0:02 ..0.04 sec after the ignition of the fuel mix of spark plugs 19, the exhaust valve 11 opens and fills the head-end volume 13 with atmosphere thus reducing pressure in this cavity.

As a result of fuel mix combustion the pressure in the combustion chamber 2 sharply increases. At the same time the backpressure valve 14 closes channel 12, preventing leakage of gas from the combustion chamber 2 in the head-end volume 13 (Fig. 2).

Under the pressure of combustion products, the piston 4 with the elastic disk 5 intensively accelerates thus accumulating the kinetic energy. At the final stage of the working piston stroke 4 the elastic disk 5 deforms the processed workpiece 24 in the matrix 9. Thus, the forming is carried out due to accumulated kinetic energy of the piston 4 and the elastic disk 5 .

After the treatment of the workpiece 24 is completed, the exhaust valve 21 opens, and the combustion products are released from the combustion chamber 2, the additional combustion chamber 18 and the working cylinder 3 . Then the piston 4 with the disk 5 get to primary position under the action of gravity. Then, having unscrewed nuts 8 , the die holder 6 is disconnected from the case 1 , and the final product is taken from the matrix 9. After that a new workpiece is placed on the surface of the ring piston 23, and the die holder 6 is connected to the case 1 . Further, the working cycle of the multichamber device is repeated in the same sequence.

The effective energy of the forming device developed through its working cycle significantly depends on the nature of the piston movement determined by pressure deviations in the combustion chamber and the working cylinder depending on design parameters of the device. To define the optimum ratios of these parameters increasing the effective energy of devices let us study the working cycle.

The working piston stroke of the multichamber device will be studied under the following assumptions: the fuel mix is burnt at the constant volume; there is no heat sink in cylinder walls; the stamped workpiece is not deformed before contacting the elastic disk. The legitimacy of these assumptions is caused by the following circumstances.

The additional combustion chamber ensures intensive combustion of the fuel mix in the combustion chamber. Due to this, the combustion lasts less than $0.01 \mathrm{sec}$. During this time the movement of the piston is small therefore the chamber volume does not increase significantly.

During the working piston stroke the heat is removed from gas to a wall of the working cylinder, however thus caused thermal losses are not too big. In piston internal combustion engines they make about $10 \%[8,9]$. The given case utilizes similar conditions, and hence, the thermal losses do not exceed $10 \%$ and do not really influence the parameters of the multichamber device.

The piston together with the elastic disk is moved under pressure deviation between the combustion chamber and the working cylinder, at the same time air from the cylinder is forced out into the atmosphere. Hence, the equation of the piston movement will be as follows:

$$
\frac{d w}{d t}=\frac{f_{c-s}}{m}\left(P_{c c}-P_{w c}\right)
$$

where $w$-piston speed; $m$ - mass of the piston with a disk; $f_{c-s}$ - cross-sectional area of the working cylinder; $P_{c c}, P_{w c}-$ pressure in the combustion chamber and the working cylinder respectively; $t$ - time. The adiabatic expansion of combustion products takes place in the course of the piston movement, then the change of gas parameters is defined by the following equation [16]:

$$
P_{K 0} V_{c c}^{k_{\Gamma}}=P_{K} V_{K 1}^{k_{a c}}
$$

where $P_{K 0}, P_{K}$ - initial and current pressure of combustion products; $V_{c c}$ - combustion chamber volume; $V_{K 1}$ - current volume of combustion products; $k_{a c}-$ adiabatic curve of combustion products. Since the fuel mix is burnt at the constant volume, then

$$
P_{K o}=\lambda P_{f}
$$

where $P_{f}$ - pressure of fuel mix; $\lambda$ - pressure ratio at the combustion of fuel mix in constant volume. The volume of combustion products increases due to piston movement, therefore

where $X$ - piston stroke.

$$
V_{K 1}=V_{K}+f_{c-s} X
$$

From the equations (2)-(4) we get the law of pressure variation of combustion products

$$
P_{\mathrm{K}}=\lambda P_{c}\left(\frac{V_{K}}{V_{K}+f_{c-s} X}\right)
$$

Let us define the law of variation of air pressure in the working cylinder. Since the mass of air in the cylinder continuously changes, the change of air change parameters follows the laws of thermodynamics of a variable-mass body:

$$
\begin{aligned}
& \frac{d P_{c}}{d t}=\frac{k_{a}-1}{V_{w c}}\left(\frac{d Q}{d t}+E_{c} G_{n}-E_{s} G_{\mathrm{p}}-\frac{k_{a}}{k_{a}-1} \frac{d L}{d t}\right), \\
& \frac{d T_{c}}{d t}=\frac{n-1}{n} \frac{T_{c}}{P_{c}} \frac{d P_{c}}{d t}, \\
& n=k_{a}-\left(k_{a}-1\right) \frac{\frac{d Q}{d t}+\left(E_{i}-k_{a} U\right) G_{n}}{\frac{d L}{d t}-\left(G_{n}-G_{\mathrm{p}}\right)\left(k_{a}-1\right) U},
\end{aligned}
$$

where $V_{\mathrm{wc}}$ - volume of the working cylinder; $P_{c}, T_{c}-$ pressure and absolute temperature of gas in the cylinder; $Q-$ amount of heat supplied to gas; $G_{n}, G_{\mathrm{p}}$ - rate of inflow and gas flow rate respectively; $E_{i}$ - energy inflow from $1 \mathrm{~kg}$ of the incoming gas, i.e. specific energy inflow; $E_{s}-$ specific energy consumption; $k_{a}$ - air adiabatic curve; $n$ - thermodynamic indicator; $u$ - specific internal energy of gas.

Let us write these equations in relation to the process within the working cylinder. The gas is not supplied to the cylinder from the outside, heat is not supplied as well, therefore:

$$
G_{n}=0 ; \Pi_{\Pi}=0 ; Q=0
$$

Then from the equations (6)-(9) we get

$$
n=k_{a} \text {, }
$$

$$
\frac{d T_{C}}{d t}=\frac{k_{a}-1}{k_{a}} \frac{T_{C}}{P_{c}} \frac{d P_{C}}{d t},
$$




$$
\frac{d P_{c}}{d t}=\frac{k_{a}-1}{V_{w c}}\left(-E_{S} G_{\mathrm{p}}-\frac{k_{a}}{k_{a}-1} \frac{d L}{d t}\right),
$$

The specific energy consumption is equal to air enthalpy in the cylinder, i.e.

$$
E_{s}=\frac{k_{a}}{k_{a}-1} R_{a} T_{c}
$$

where $R_{a}$ - gas constant of air. The air consumption from the cylinder depends on the $P_{c} / P_{\mathrm{a}}$ ratio, where $P_{\mathrm{a}}$ - atmospheric pressure. In this case the above-critical pressure deviation takes place, therefore gas consumption is defined by the following dependence [16]:

$$
\begin{gathered}
G=\mu f_{\mathrm{K}} g P_{c} \sqrt{\frac{k_{\mathrm{B}}}{R_{a} T_{c}}} \\
g=\left(\frac{2}{K_{a}+1}\right)^{\frac{k_{a}+1}{2\left(k_{a}-1\right)}}
\end{gathered}
$$

where $f_{\mathrm{K}}$ - area of passage of the exhaust valve; $\mu$ - flowrate ratio. The elementary work of the air when moving the piston equals

$$
d L=P_{c} d V_{w c}=-P_{c} f_{c} d X
$$

The piston movement and speed are interrelated by the following equation:

$$
\frac{d X}{d t}=W
$$

Then from the equation (15) we get:

$$
\frac{d L}{d t}=-P_{ц} f_{ц} W
$$

The current volume of the working cylinder equals:

$$
V_{w c}=f_{c} h-f_{c} X=f_{c}(h-X),
$$

where $h$-initial height of the cylinder equal to the distance from the elastic disk surface up to the processed workpiece. By inserting expressions (13), (14), (17), (18) in the equation (12) we get the equation describing air pressure variation in the cylinder:

$$
\frac{P_{c}}{d t}=\frac{k_{a}}{f_{c}(h-X)}\left(f_{c} P_{c} W-m f_{\mathrm{\kappa}} g P_{c} \sqrt{k_{a} R_{a} T_{c}}\right) .
$$

The effective energy of the device, ensuring the forming process, is equal to the kinetic energy of the piston with the elastic disk accumulated during the entire working cycle:

$$
E_{\ni}=\frac{1}{2} m W^{2} \text {. }
$$

Let us put the following dimensionless values:

$x=\frac{X}{h}, \quad \tau=\frac{t}{t_{z}}, \quad \bar{W}=\frac{h W}{t_{z}}, \quad \overline{P_{\mathrm{K}}}=\frac{P_{\mathrm{K}}}{P_{\mathrm{c}}}, \quad \overline{P_{c r}}=\frac{P_{c r}}{P_{\mathrm{c}}}, \quad v_{c}=\frac{f_{c} h}{V_{\mathrm{K}}}$,

where $x$-relative piston stroke; $\tau$-dimensionless time; $\bar{W}$ - dimensionless speed of the piston; $\bar{P}_{\mathrm{K}}, \overline{P_{c r}}-$ dimensionless pressure of gas in the combustion chamber and the cylinder respectively; $v_{c}$ - relative volume of the cylinder; $t_{z}$ - time of fuel mix combustion in the combustion chamber. By inserting these values in the equations (1), (5), (11), (17), (19), we get the following system of dimensionless equations:

$$
\begin{aligned}
& \frac{d X}{d \tau}=\bar{W}, \\
& \frac{d \bar{W}}{d \tau}=a\left(\overline{P_{\mathrm{K}}}-\overline{P_{c r}}\right),
\end{aligned}
$$

$$
\begin{aligned}
& \frac{d \overline{P_{c r}}}{d \tau}=\frac{k_{a}-1}{1-X}\left(\overline{P_{2}} \bar{W}-b \overline{P_{c r}} \sqrt{\overline{T_{c}}}\right), \\
& \frac{d \overline{T_{2}}}{d \tau}=\frac{k_{a}-1}{k_{a}} \frac{\overline{T_{c}}}{\overline{P_{c r}}}\left(\overline{P_{2}} \bar{W}-b \overline{P_{c r}} \sqrt{\overline{T_{c}}}\right) \\
& P_{1}=\lambda\left(1+v_{c} X\right)^{-K_{g}} \\
& a=\frac{f_{c} t_{z}^{2} P_{c}}{m h} \\
& b=\frac{t_{z}}{f_{c} h} \mu f_{k} g \sqrt{k_{\mathrm{B}} R_{a} T_{c}},
\end{aligned}
$$

The system of dimensionless equations (21)-(25) describes the movement of the piston and change of gas parameters in the combustion chamber and the working cylinder. Numerically, this system of equations is solved by the Runge-Kutta method [15] in Octave medium. The analysis of the obtained solution showed that the nature of the piston movement and change of gas parameters in the combustion chamber and the cylinder most likely depend on the fuel mix pressure $\mathrm{P}_{\mathrm{s}}$, relative volume of the cylinder and the $\mathrm{f}_{\mathrm{c}} / \mathrm{f}_{\mathrm{k}}$ ratio. The optimum range of $P_{\mathrm{c}}$ variation is within 0.3-0.7 MPa. The increase of $P_{s}$ increases the effective energy of the multichamber device thus ensuring forming of parts with bigger thickness at given dimensions of the multichamber device. However, the $\mathrm{P}_{\mathrm{s}}$ increase higher than $0.7 \mathrm{MPa}$ is not rational since for air compression this requires a more powerful compressor working on three-phase current.

The optimum size of the relative volume of the cylinder $v_{c}$ is within $1.3 \ldots 2.5$. The increase of $v_{c}$ increases the effective energy of the forming device. However, with the increase of $v_{c}$ higher than 2.5 the increase of effective energy of the device is insignificant, unlike its overall dimensions, which increase significantly.

The $f_{c} / f_{k}$ ratio of the areas, which may vary within wide limits exerts the most significant impact on the piston movement.

Thus, the piston makes oscillating movements along the cylinder length. Naturally, such movement of the piston is absolutely unacceptable for the forming process since in this case the deformation of the processed workpiece will begin after the piston makes several or numerous oscillations and by this time its kinetic energy will significantly decrease. For effective completion of the forming process the piston shall move rapidly thus continuously accumulating the kinetic energy. The analysis showed that for the maximum pressure of fuel mix equal $0.7 \mathrm{MPa}$ the $\mathrm{f}_{\mathrm{k}} / \mathrm{f}_{\mathrm{c}}$ ratio shall be at least 0.1 .

This multichamber device can also be used for pressing of concrete and reinforced concrete products.

The developed multichamber device will be efficient in mechanical engineering, aircraft and defense industry.

\section{CONCLUSIONS}

The advanced multichamber device has no leakage of combustion products from the combustion chamber into the head-end volume of the working cylinder. Due to this fact, the kinetic energy of the piston fostering the deformation of the processed workpiece is much higher in this device in 
comparison with the existing analogues. It increases the technological potential of the device, i.e. makes it possible to receive products from sheet workpieces of bigger thickness and from hardly deformable materials.

\section{References}

[1] Botashev A.Yu., Bisilov N.U. "Study of gas sheet-metal forming with bilateral heating of a workpiece," Blank production in mechanical engineering, No. 3, pp. 25-28, 2013.

[2] V.L. Kukhar, V.Yu. Legeyda, A.E. Kireeva, "Envelop forming from conical workpiece via uniform gas pressure," Press forging. Treatment of materials under pressure, No. 9, pp. 43-45, 2010

[3] R.S. Malsugenov, "Development of device for gas forming of panels of spiral heat exchangers," Current state of natural and technical sciences: proceedings of the XVI International Scientific and Practical Conference. Moscow: Sputnik publishing house, pp. 36-41, 2014.

[4] Malsugenov R.S. "Development, creation and testing of gas forming device with backpressure," Development of technical science in the modern world, Collection of scientific works following the results of the international scientific and practical conference. Voronezh, 2015.

[5] A.Yu. Botashev, A.A. Musayev, "Development, study and creation of two-chamber device for gas sheet forming" Blank production in mechanical engineering, No. 3, pp. 20-23, 2012.

[6] Musayev A.A. "Source data for the development of a trial sample of the two-chamber device for gas sheet forming," News of higher educational institutions. Mechanical engineering, No. 3, pp. 43-48, 2012.

[7] Patent 169195. Russian Federation, RU 169195 MPK B21D 26/08., Impulse-forming machine for materials treatment under pressure, utility patent / A.Yu. Botashev, A.A. Musayev, M.A. Betrakhmanov; published on 09.03.2017, Bulletin No. 7
[8] Dyachenko V.G. Theory of internal combustion engines. Study manual. Kharkiv: Kharkiv National Automobile and Highway University, 2009.

[9] Yu.L. Kovylov. Theory of working processes and modeling of processes of internal combustion engines: Study manual. Samara: Publishing house of Samara University, 2013.

[10] A. Honda, M. Suzuki, "Sheet Metal Forming by Using Gas Imploding Detonation," Article in Journal of Materials Processing Technology, 85(1):198-203, January 1999.

[11] T.M. Mostofi, H. Babaei, M. Alitavoli, "The influence of gas mixture detonation loads on large plastic deformation of thin quadrangular plates: Experimental investigation and empirical modelling," Article THIN WALL STRUCT, Sep 2017.

[12] H. Babaei, T.M. Mostofi, M. Namdari-Khalilabad, M. Alitavoli, K. Mohammadi, "Gas mixture detonation method, a novel processing technique for metal powder compaction: Experimental investigation and empirical modeling", Article POWDER TECHNOL, Jun 2017.

[13] S.P. Patil, M. Popli, V. Jenkouk, B. Markert. Numerical modelling of the gas detonation process of sheet metal forming. Article J Phys Conf., Aug 2016

[14] H. Babaei, T. Mirzababaie Mostofi, M. Alitavoli, A. Darvizeh. "Empirical Modelling for Prediction of Large Deformation of Clamped Circular Plates in Gas Detonation Forming Process," Article EXP TECHNIQUES, Jul 2016.

[15] Zausayev A.F. Differential methods for the solution of standard differential equations: Study manual. Samara: Samara State Technical University, 2010, pp. 100.

[16] Erofeyev V.L., Semyonov P.D., Pryakhin A.S. "Thermal engineering engineer: Study manual for higher educational institutions," Under the editorship of the Dr.Sci.Tech., prof. V.L. Erofeyev. Moscow: Akademkniga, 2008. 